\title{
Involvement of Cold Inducible RNA-Binding Protein in Severe Hypoxia-Induced Growth Arrest of Neural Stem Cells In Vitro
}

\author{
Qian Zhang ${ }^{1}$ - Ya-Zhou Wang ${ }^{2}$ - Wenbin Zhang ${ }^{1}$ - Xiaoming Chen ${ }^{1} \cdot$ Jiye Wang ${ }^{1}$. \\ Jingyuan Chen ${ }^{1}$ - Wenjing Luo ${ }^{1}$
}

Received: 31 August 2015 / Accepted: 28 January 2016 /Published online: 1 March 2016

(C) The Author(s) 2016. This article is published with open access at Springerlink.com

\begin{abstract}
Neonatal hypoxia is the leading cause of brain damage with birth complications. Many studies have reported proliferation-promoting effect of mild hypoxia on neural stem cells (NSCs). However, how severe hypoxia influences the behavior of NSCs has been poorly explored. In the present study, we investigated the effects of 5, 3, and $1 \%$ oxygen exposure on NSCs in vitro. MTT, neurosphere assay, and 5-ethynyl-2'-deoxyuridine (EdU) incorporation revealed a quick growth arrest of C17.2 cells and primary NSCs induced by $1 \%$ oxygen exposure. Cell cycle analysis showed that this hypoxia exposure caused a significant increase of cells in $\mathrm{G} 0$ / G1 phase and decrease of cells in S phase that is associated with decrease of Cyclin D1. Interestingly, the expression of cold inducible RNA-binding protein (CIRBP), a cold responsive gene reacting to multiple cellular stresses, was decreased in parallel with the $1 \%$ oxygen-induced proliferation inhibition. Forced expression of CIRBP under hypoxia could restore the proliferation of NSCs, as showed by EdU incorporation and cell cycle analysis. Furthermore, the expression of Cyclin D1 under hypoxia was also restored by CIRBP
\end{abstract}

Qian Zhang and Ya-Zhou Wang contributed equally to this work.

Wenjing Luo

luowenj@fmmu.edu.cn

1 Department of Occupational and Environmental Health, the Ministry of Education Key Lab of Hazard Assessment and Control in Special Operational Environment, School of Public Health, Fourth Military Medical University, 169 Chang Le Xi Road, Xi'an, Shaanxi 710032, China

2 Department of Neurobiology and Collaborative Innovation Center for Brain Science, School of Basic Medicine, Fourth Military Medical University, 169 Chang Le Xi Road, Xi'an, Shaanxi 710032 , China overexpression. Taken together, these data suggested a growth-suppressing effect of severe hypoxia on NSCs and, for the first time, revealed a novel role of CIRBP in hypoxia-induced cell cycle arrest, suggesting that modulating CIRBP may be utilized for preventing hypoxia-induced neonatal brain injury.

Keywords Severe hypoxia $\cdot$ Neural stem cells $\cdot$ CIRBP . Proliferation

\section{Introduction}

Neonatal hypoxia usually leads to permanent neurological handicap, practically because the immature brain is at a critical state of dynamic development. Extensive studies have been conducted on the apoptosis-inducing effects of hypoxia on neurons and oligodendrocytes [1-4]. Neural stem cells (NSCs), the major cell type that bears the capacity of regenerating lost nerve cells, are mainly reserved in the subventricular zone (SVZ). In rodents, the region of SVZ is at its maximum size at neonatal stage [5]. Therefore, it is of importance to explore the effects of neonatal hypoxia on the behavior of NSCs. In comparison with the oxygen tension in blood which is $14 \%$, brain tissue is exposed to hypoxia, with oxygen tension varies from $0.55 \%$ in the midbrain to $8 \%$ in regions near the pia $[6,7]$. Therefore, it has been proposed that hypoxia may be beneficial for NSCs, as some studies have showed that mild hypoxia (2.5-5\%), mimicking the in vivo oxygen level of embryonic brain, increases the proliferation of NSCs [8-10]. However, the long-term neurogenesis deficiency observed after neonatal hypoxia stress strongly suggests a probably detrimental effect of severe hypoxia $(<1 \%)$, which occurs under pathological conditions such 
as ischemia and tumor growth $[6,7,11-14]$, on the proliferation of NSCs which remains poorly investigated.

Cold inducible RNA-binding protein (CIRBP) is initially identified as a member of cold shock proteins and can be induced by multiple stressful conditions such as moderate hypothermia, hypoxia, and ultraviolet irradiation [3, 15-20]. Later studies revealed its participation as RNA chaperones in circadian rhythm regulation, neural development, tumorigenesis, and inflammation [21-24]. Of note, recent studies have demonstrated an involvement of CIRBP in the proliferation of tumor cells and germ cells [25-30]. Under low temperature, CIRBP is reportedly activated and contributed to the preservation of the stemness of NSCs [31]. How CIRBP is regulated and involved in the response of neural stem cells to severe hypoxia remains largely unclear.

In the present study, we explored the effects of $1 \% \mathrm{O}_{2}$, a condition which has been adopted to mimic the ischemic attachment in vivo [12,19,32], on the proliferation of NSCs and expression of CIRBP in NSCs and further examined the role of CIRBP in neural stem cells under severe hypoxia.

\section{Materials and Methods}

\section{Cell Culture}

Mouse NSC line C17.2 [33] was cultured in Dulbecco's modified Eagle's medium (DMEM) (Invitrogen) containing $2 \mathrm{mM}$ L-glutamine (Invitrogen), $10 \%$ fetal bovine serum (FBS) (Sijiqing Biotech, China), $5 \%$ horse serum (Gibco), 100 units $/ \mathrm{mL}$ of penicillin, and $100 \mu \mathrm{g} / \mathrm{mL}$ of streptomycin. The cultures were maintained in a standard humidified incubator in $5 \% \mathrm{CO}_{2}$ at $37{ }^{\circ} \mathrm{C}$, with fresh medium replaced every 2 days, and split 1:4 when the cells reached $90 \%$ confluence.

Primary neural stem cells were isolated from newborn SD rat cerebral cortex and cultured in uncoated $25-\mathrm{mL}$ flasks in DMEM/F-12 medium (Invitrogen) containing N2 and B27 supplements (Invitrogen) plus basic fibroblast growth factor (Promega, $20 \mathrm{ng} / \mathrm{mL}$ ) and epidermal growth factor (Promega, $20 \mathrm{ng} / \mathrm{mL}$ ). After 5-7 days culture in vitro (DIV), the primary neurospheres were collected and dissociated with $0.05 \%$ trypsin plus $200 \mathrm{mM}$ EDTA for $10 \mathrm{~min}$ at $37{ }^{\circ} \mathrm{C}$ and mechanically triturated with fire-polished glass pipettes. The single cells were resuspended at a density of 50,000 cells per $\mathrm{mL}$ of serum-free medium and cultured for 3-5 days. The number and diameters of neurospheres were assessed as described [34].

\section{Hypoxia Exposure}

Hypoxia environment was made by placing cells in a humidified microaerophilic incubation system (DWS HypOxystation) with a calibrated gas containing $1 \% \mathrm{O}_{2}$ or
$3 \% \mathrm{O}_{2}$ at $37{ }^{\circ} \mathrm{C}\left(\mathrm{CO}_{2}\right.$ was adjusted at $5 \%$ in both conditions $)$. The cells were left in the incubator at $37{ }^{\circ} \mathrm{C}$ for different durations. The control cultures were incubated in normoxic conditions all the time for the same durations.

\section{MTT Assay}

C17.2 NSCs were plated in 96-well plates at 5000 cells per well in growth media cultured in DWS HypOxystation incubator perfused with a calibrated gas mixture of $1 \% \mathrm{O}_{2}$ or $3 \%$ $\mathrm{O}_{2}$ with $5 \% \mathrm{CO}_{2}$ at $37^{\circ} \mathrm{C}$ or in a normal incubator with $21 \%$ $\mathrm{O}_{2}$ and $5 \% \mathrm{CO}_{2}$ at $37^{\circ} \mathrm{C}$ for $0,12,24,36$, and $48 \mathrm{~h}$, respectively. Twenty microliters of MTT stock solution $(5 \mathrm{mg} / \mathrm{mL})$ was added to the medium for $4 \mathrm{~h}$ at $37{ }^{\circ} \mathrm{C}$. Then the supernatant was removed and replaced with $150 \mu \mathrm{L}$ of dimethyl sulfoxide (DMSO) for $10 \mathrm{~min}$ at $37{ }^{\circ} \mathrm{C}$ until crystals were dissolved. The plates were shaken vigorously for $10 \mathrm{~min}$ to ensure complete dissolvent. MTT quantification was measured at $490 \mathrm{~nm}$ with a microplate reader.

\section{EdU Incorporation Assay}

The EdU incorporation assay was performed with a Cell-Light EdU kit (Ribobio Co., Ltd., Guangzhou, China) according to the manufacturer's instructions. Briefly, C17.2 NSCs were cultured in six-well plates coated with poly-D-lysine at a cell density of $1.5 \times 10^{5}$ cells per well, and the cells were then labeled with $50 \mu \mathrm{M} \mathrm{EdU} \mathrm{(1:1000)} \mathrm{and} \mathrm{incubated} \mathrm{for} \mathrm{an} \mathrm{addi-}$ tional $2 \mathrm{~h}$ before the cells were fixed with $4 \%$ formaldehyde for $15 \mathrm{~min}$ at room temperature and treated with $0.5 \%$ Triton X-100 for $20 \mathrm{~min}$ at room temperature for permeabilization. After washing with PBS for three times, each well of cells was reacted with $100 \mu \mathrm{L}$ of $1 \times$ ApolloIV reaction cocktail for $30 \mathrm{~min}$. Subsequently, the nucleus was counterstained with Hoechst 33342 and the cells were observed using a fluorescence microscope (IX70, Olympus).

\section{Plasmid Construction and Transfection}

Human CIRBP complementary DNA (cDNA) clone (NC_000019) in pEGFP-N2 vector was a gift from Dr. Wenbin Zhang in the lab. The control transfection was performed by pEGFP-N2 vector without CIRBP. Overexpression of CIRBP by these cells was verified by Western blotting using anti-CIRBP antibody as described below.

Transfection of C17.2 neural stem cells with CIRBP cDNA was performed by using Lipofectamine 2000 transfection reagent (Invitrogen, USA) according to the manufacturer's procedure. In brief, cells were plated in six-well plates (Nunc) at a cell density of 10,000 cells per well and were allowed to grow overnight to achieve $80 \%$ confluency. Transfection complexes, consisting of $2.5 \mu \mathrm{g}$ pEGFP-N2 vector plasmid 
DNA or pEGFP-N2-CIRBP plasmid DNA and $6 \mu \mathrm{L}$ Lipofectamine reagent, were added to the wells in OptiMEM® Medium (Invitrogen, USA). Cells were analyzed $24 \mathrm{~h}$ after lipofection for transfection efficiency and viability.

Transfection of primary neural stem cells with CIRBP cDNA was performed by electroporation. In brief, the primary neurospheres were collected when diameters ranged between 80 and $120 \mu \mathrm{m}$, and dissociated with $0.05 \%$ trypsin and $200 \mathrm{mM}$ EDTA for $10 \mathrm{~min}$ at $37^{\circ} \mathrm{C}$, and mechanically triturated with fire-polished glass pipettes. The single cells were resuspended at a density of $1 \times 10^{7}$ cells per $\mathrm{mL}$ of serum-free Opti-MEM® medium. Mixture of the single cell suspension with plasmid DNA makes its final concentration reached $1 \times 10^{6}$ cells and $10 \mu \mathrm{g}$ plasmid DNA $(1 \mu \mathrm{g} / \mu \mathrm{L})$ in $100 \mu \mathrm{L}$ solutions. Two pulses of $125 \mathrm{~V}, 7.5 \mathrm{~ms}$ each at $50 \mathrm{~ms}$ intervals, were delivered through electroporation cuvettes (2 mm gap) with a NEPA21 electroporator. After electroporation, the mixture in the cuvette was supplemented with $2 \mathrm{~mL}$ serum-free neural stem cell media and transferred gently into a prepared uncoated six-well plate. Cells were analyzed $48 \mathrm{~h}$ after electroporation for transfection efficiency and viability.

\section{Real-time Reverse Transcription-PCR}

Cells were harvested for total RNA isolation using Trizol reagent (Invitrogen) according to manufacturer's instructions. After reverse transcription, real-time PCR was performed using ABI7500 system. The reaction was made in $10 \mu \mathrm{L}$ of SYBR Green I (Takara), $0.5 \mu \mathrm{M}$ of each $5^{\prime}$ and 3' primer, $2 \mu \mathrm{L}$ cDNA, and $\mathrm{H}_{2} \mathrm{O}$ to a final volume of $20 \mu \mathrm{L}$. Samples were amplified for 40 cycles with a denaturation at $95{ }^{\circ} \mathrm{C}$ for $5 \mathrm{~s}$, annealing, and extension at $57.5^{\circ} \mathrm{C}$ for $34 \mathrm{~s}$. SYBR green fluorescence was measured to determine the amount of double-stranded DNA. To discriminate specific from nonspecific cDNA products, a melting curve was obtained at the end of each run. Relative messenger RNA (mRNA) levels of target genes were normalized to GAPDH and compared with the control using the $2^{-\mathrm{ddCt}}$ methods. The primer sequences used in this study were listed below.

For rat CIRBP,

5'-TTACTGTTTACCATGAGCCATG-3' (forward) and 5'-CACACAACCCGACAATTTAG-3' (reverse).

For rat glyceraldehyde-3-phosphate dehydrogenase (GAPDH),

5'-TACCCACGGCAAGTTCAACG-3' (forward) and 5'-CACCAGCATCACCCCATTTG-3' (reverse).

For mouse CIRBP,

5'-TCCAGAGACTACTATGCCAG-3' (forward) and 5'-GAACGGAAAGGACTACAAAA-3' (reverse).

For mouse glyceraldehyde-3-phosphate dehydrogenase (GAPDH),
5'-AATGGTGAAGGTCGGTGTGA-3' (forward) and 5'-GCTCCTGGAAGATGGTGATG-3' (reverse).

For mouse Cyclin D1,

5'-GGATGCTGGAGGTCTGTGAG-3' (forward) and 5'-CGGCAGTCAAGGGAATGGTC-3' (reverse).

\section{Cell Cycle Analysis}

For analysis of cell cycle, cells with different treatments were trypsinized, washed twice in PBS, and fixed overnight at $-20{ }^{\circ} \mathrm{C}$ in $300 \mu \mathrm{L}$ PBS and $700 \mu \mathrm{L}$ ethanol. The fixed cells were spun down gently in $200 \mu \mathrm{L}$ extraction buffer $\left(0.1 \%\right.$ Triton X-100, $45 \mathrm{mM} \mathrm{Na}_{2} \mathrm{HPO}_{4}$ and $2.5 \mathrm{mM}$ sodium citrate) at $37{ }^{\circ} \mathrm{C}$ for $20 \mathrm{~min}$ and then stained with propidium iodide (BD Biosciences, San Jose, CA, USA) $(50 \mu \mathrm{g} / \mathrm{mL})$ containing $50 \mu \mathrm{g} / \mathrm{mL}$ RNase A for $30 \mathrm{~min}$ at $37{ }^{\circ} \mathrm{C}$ in the dark, and subsequently analyzed by FACS. The experiment was repeated for at least three times, and the data were analyzed using CellQuestk and ModFitk software.

\section{Western Blotting Analysis}

Cells were washed twice with ice-cold PBS and lysed with buffer containing Tris-HCl (50 mM, pH=7.4), NP-40 (1\%), Na-deoxycholate $(0.25 \%), \mathrm{NaCl}(150 \mathrm{mM})$, EDTA (1 mM), PMSF (1 mM), $\mathrm{Na}_{3} \mathrm{VO}_{4}(1 \mathrm{mM})$, and NaF (1 mM) for total extract. Protein concentration was determined by the BCA protein assay (Pierce Chemical Co.). Equal amounts of cell lysates were separated by $10 \%$ SDSpolyacrylamide gel electrophoresis and electro-transferred onto nitrocellulose membranes. Membranes were then incubated in blocking solution (5\% nonfat milk in $20 \mathrm{mM}$ Tris-HCl, $150 \mathrm{mM} \mathrm{NaCl}, 0.1 \%$ Tween-20) (TBS-T), followed by incubation with the indicated antibodies at $4{ }^{\circ} \mathrm{C}$ overnight. The membranes were then washed in TBS-T and incubated with HRP-conjugated secondary antibodies for $1 \mathrm{~h}$ at room temperature. Enhanced chemiluminescence (ECL) Western blotting substrate (Pierce) was used to detect the immunoreactive signals with an ECLbased FluorChem FC2 image system (Alpha Innotech). Rabbit anti-CIRBP was purchased from ProteinTech, and rabbit anti-Cyclin D1 was from Santa Cruz Biotechnology. All Western blotting analyses were performed in triplicates. FluorChem FC2 software was used to analyze the gray values of the bands in each group.

\section{Statistics}

Data were presented as the mean \pm S.E. Statistical analysis of the data for multiple comparisons was performed by analysis of variance. $T$ test and ANOVA were adopted for comparison. A value of $p<0.05$ was considered statistically significant. 

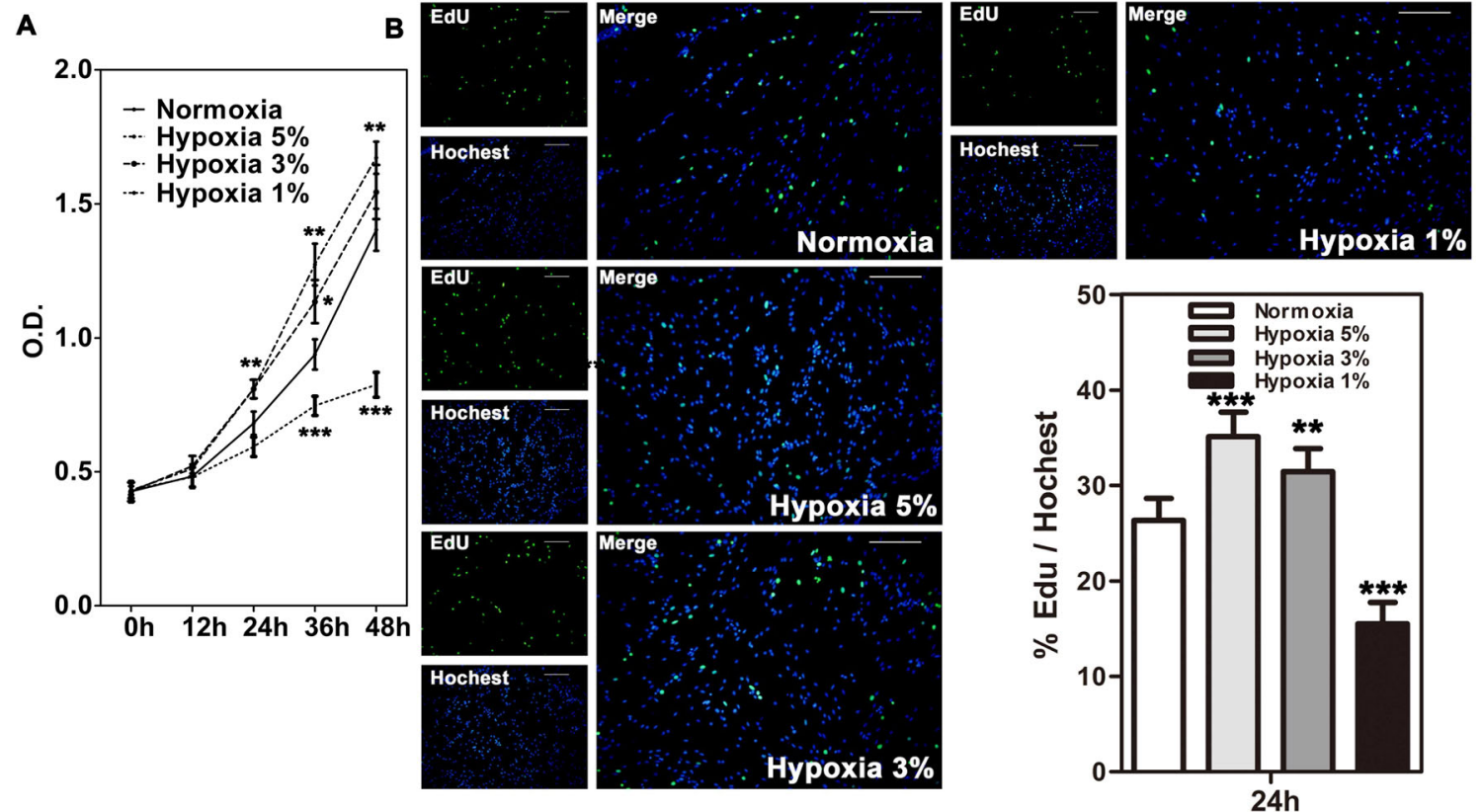

C
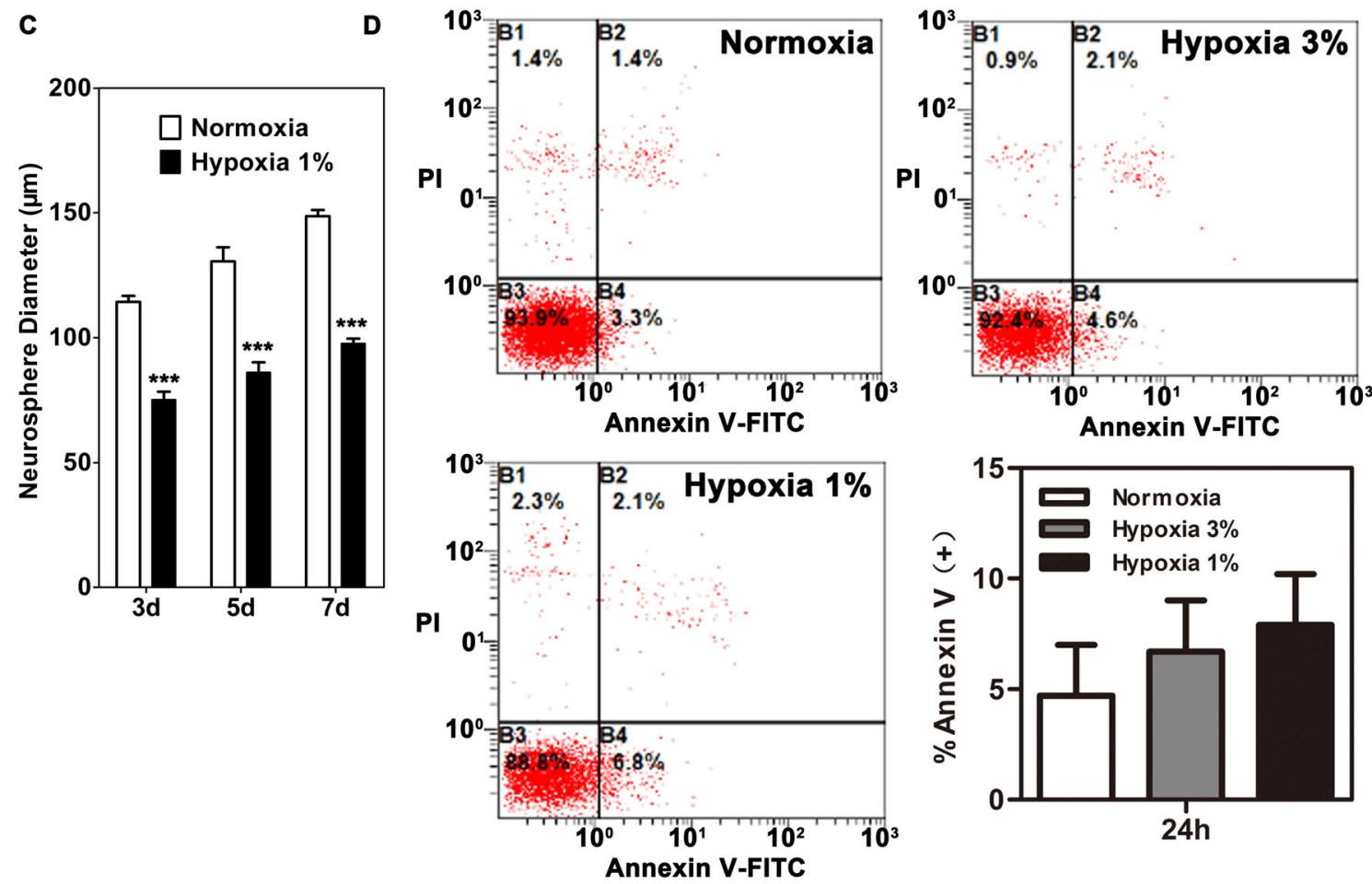

Fig. 1 Effects of hypoxia on the proliferation of NSCs. a C17.2NSC cells were cultured under normoxia or hypoxia for $0,12,24$, 36 , and $48 \mathrm{~h}$. Cell proliferation was assessed using MTT assay. Notice the increase of O.D. values by $5 \% \mathrm{O}_{2}$ and decrease of O.D. values by $1 \% \mathrm{O}_{2}$. $* * *$ depicts significant decrease of O.D. values after exposure to hypoxia $(p<0.001)$. b EdU immunostaining of C17.2 NSCs cultured under normoxic or hypoxic conditions for $24 \mathrm{~h}$ and quantification of EdU+ cells. $* *$ indicates a significant decrease of EdU+ cells in NSCs cultured with $1 \% \mathrm{O}_{2}(p<0.001)$. Bars $=100 \mu \mathrm{m}$. c Effect of $1 \% \mathrm{O}_{2}$ on the formation of neurospheres. Primary neural stem/progenitor cells were cultured in normoxia or $1 \% \mathrm{O}_{2}$ for 7 days. The diameters of neuospheres were measured on days 3,5 , and 7 . $* * *$ depicts smaller neurospheres in cells cultured with $1 \% \mathrm{O}_{2}$ than those in cells in normoxia $(p<0.001)$. d Effect of $1 \% \mathrm{O}_{2}$ or $3 \% \mathrm{O}_{2}$ on the apoptosis of NSCs after $24 \mathrm{~h}$ exposure to hypoxia 
A

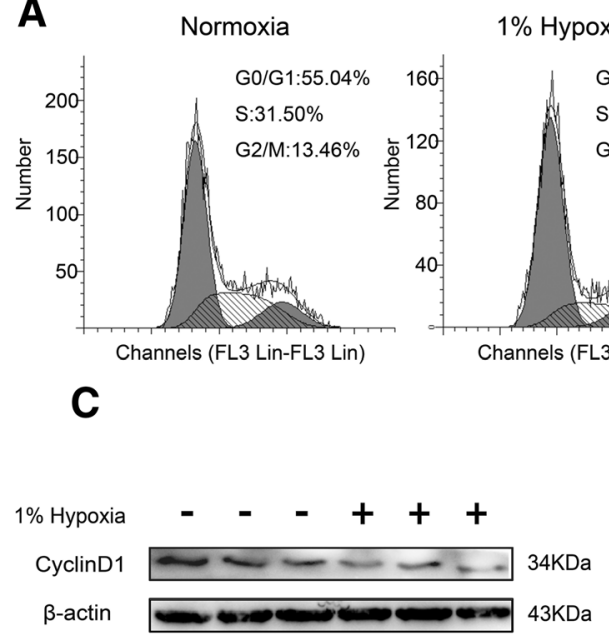

Fig. 2 Effect of $1 \% \mathrm{O}_{2}$ on the cell cycle of $\mathrm{C} 17.2$ NSCs. a A representative plot of cell cycle from one of three independent experiments. The first gray area (close to Y axis), the hatched area, and the second gray area (distant to Y axis) represent the number of cells in G1/G0, S phase, and G2 phase, respectively. b Percentages of cells in G1/ $\mathrm{G} 0, \mathrm{~S}$, and G2/M phase in control and hypoxia-exposed groups. ** indicates significant difference between the control and hypoxia-exposed groups $(p<0.01)$. c Western blotting analysis of Cyclin D1 in NSCs

\section{B}
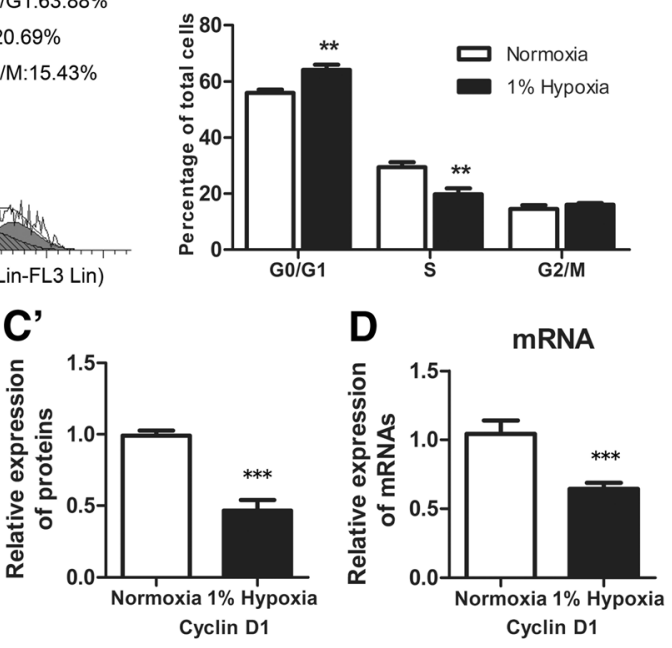

cultured in normoxia or $1 \% \mathrm{O}_{2}$ for $24 \mathrm{~h}$ (left). Samples in each group were from three independent experiments. The relative expression levels of Cyclin D1 protein were quantified (right). $\beta$-actin served as a protein loading control. d Real-time RT-PCR analysis of Cyclin D1 mRNA in NSCs cultured in normoxia or $1 \% \mathrm{O}_{2}$ for $24 \mathrm{~h}$. GAPDH served as an internal control. *** depicts the significant decrease of Cyclin D1 at both protein (c) and mRNA (d) levels after severe hypoxia exposure $(p<0.001)$

two different oxygen concentrations $\left(21 \% \mathrm{O}_{2}\right.$ normoxia group vs $1 \% \mathrm{O}_{2}$ hypoxia group) and examined the size of neurospheres. The diameters of neurospheres on days 3,5 , and 7 days in vitro (DIV) were measured and compared. Primary neural stem/progenitor cells gave rise to smaller neurosphere in $1 \% \mathrm{O}_{2}$ than those cultured in normoxia with mean neurosphere diameters of $75.13 \pm 31.21 \mu \mathrm{m}$ vs $114.37 \pm 39.55 \mu \mathrm{m}$ on day 3 , $86.11 \pm 27.67 \mu \mathrm{m}$ vs $130.67 \pm 46.46 \mu \mathrm{m}$ on day 5 , and 97.68 $\pm 26.00 \mu \mathrm{m}$ vs $148.60 \pm 45.50 \mu \mathrm{m}$ on day 7 (Fig. 1c).

To examine whether $1 \% \mathrm{O}_{2}$ affected the survival of NSCs, we analyzed the expression of annexin- $\mathrm{V}$, a marker of apoptosis. No significant difference of annexin- $\mathrm{V}$ expression was detected among cells in normal condition, $1 \% \mathrm{O}_{2}$, and $3 \% \mathrm{O}_{2}$ after $24 \mathrm{~h}$ exposure when EdU incorporation has been reduced in $1 \% \mathrm{O}_{2}$ (Fig. 1d). Therefore, it seems that $1 \% \mathrm{O}_{2}$ may induce growth arrest of NSCs without affecting cell survival.

\section{Cell Cycle Arrest of C17.2 NSCs After Severe Hypoxic Stimulation}

We then focused on the effects of $1 \% \mathrm{O}_{2}$ on the proliferation of NSCs. Cell cycle analysis was performed in both control NSCs. To further confirm the growth-inhibiting effect of $1 \%$ on NSCs, we cultured primary neural stem/progenitor cells in 


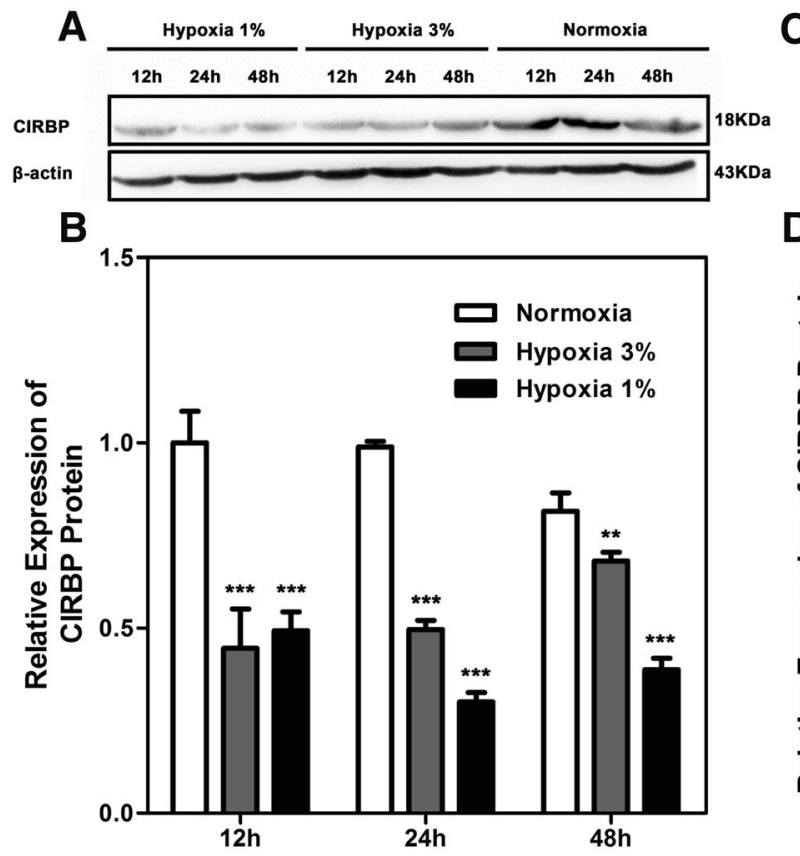

Fig. 3 Effect of hypoxia on the expression of CIRBP in NSCs. a, b Expression of CIRBP in C17.2 NSCs after exposure to 1 or $3 \% \mathrm{O}_{2}$. Notice the suppression of CIRBP in $1 \% \mathrm{O}_{2}$ and the transient suppression of CIRBP in $3 \% \mathrm{O}_{2}$. a-d Expression of CIRBP in primary NSCs at different time points after exposure to $1 \% \mathrm{O}_{2}$. e Real-time RT-

and $1 \% \mathrm{O}_{2}$-treated $\mathrm{C} 17.2 \mathrm{NSCs}$. In the control group, approximately $55.04 \%$ of cells stayed at in G1 phase, $31.50 \%$ at S phase, and $13.46 \%$ at $\mathrm{G} 2 / \mathrm{M}$ phase. In the hypoxia exposure group, approximately $63.88 \%$ of cells were in G1 phase, $20.69 \%$ in S phase, and $15.43 \%$ in G2/M phase (Fig. 2a). Statistical analysis showed a significant increase of cells in G0/G1 and decrease of cells in S phase by $1 \% \mathrm{O}_{2}$ (Fig. 2b).

To elucidate the molecular mechanisms underlying hypoxia-induced cell cycle arrest, we examined the expression levels of Cyclin D1 that plays a crucial role in controlling cell cycle progression from $\mathrm{G} 0-\mathrm{G} 1$ to $\mathrm{S}$ phase and acts as a sensor for cell cycle machinery in response to stress, cytokine, and growth factor stimulation. As shown in Fig. 2c, the expression of Cyclin D1 protein was significantly decreased in cells exposed to hypoxia for $24 \mathrm{~h}$ (Fig. 2c). Reduction of Cyclin D1 was further confirmed by real-time RT-PCR analysis that showed decreased levels of Cyclin D1 mRNA in hypoxiaexposed cells (Fig. 2d). Taken together, these data suggest that $1 \% \mathrm{O}_{2}$ might induce the cell cycle arrest of NSCs.

\section{Severe Hypoxia Exposure Decreases the Expression of CIRBP in NSCs}

To explore the possible mechanism for the severe hypoxiainduced growth arrest of NSCs, we examined the expression of CIRBP, a stress response protein that has been thought to be involved in regulating the proliferation of tumor cells [25,27], in C17.2 NSCs under the conditions of hypoxia. Western blotting showed a significant decrease of CIRBP at $24 \mathrm{~h}$ in $3 \% \mathrm{O}_{2}$ which recovered to approximately $80 \%$ of the normal expression level at $48 \mathrm{~h}$ (Fig. 3a, b).

The effect of $1 \% \mathrm{O}_{2}$ on the expression of CIRBP was further investigated using primary neural stem cells that were cultured under normoxia or $1 \% \mathrm{O}_{2}$ for $1,2,3$, and 5 days. The levels of CIRBP protein in hypoxia-exposed cells at all time points were significantly lower than those in normoxia groups (Fig. 3c, d). In addition, a significantly lower level of CIRBP mRNA was also detected in $1 \%$ hypoxia-treated primary neural cells from $24 \mathrm{~h}$ to 5 days exposure (Fig. 3e). These data demonstrated that severe hypoxia exposure decreased the expression of CIRBP in both C17.2 NSCs and primary NSCs, indicating CIRBP may be involved in the growth inhibitory effects of hypoxia on NSCs.

\section{Overexpression of CIRBP Rescues the Growth Arrest of NSCs Caused by Severe Hypoxia}

To investigate the potential link between the reduction of CIRBP and hypoxia-induced NSC growth arrest, we transfected C17.2 NSCs with p-EGFP-N2-CIRBP plasmid and examined the cell proliferation by EdU incorporation assay after exposure to $1 \% \mathrm{O}_{2}$ for $24 \mathrm{~h}$. Overexpression of CIRBP in transfected cells was confirmed by Western blotting (Fig. 4a). Under normoxic culture condition, 
A

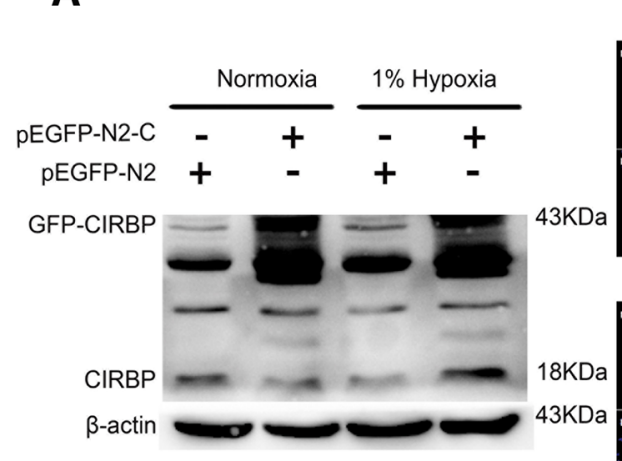

C

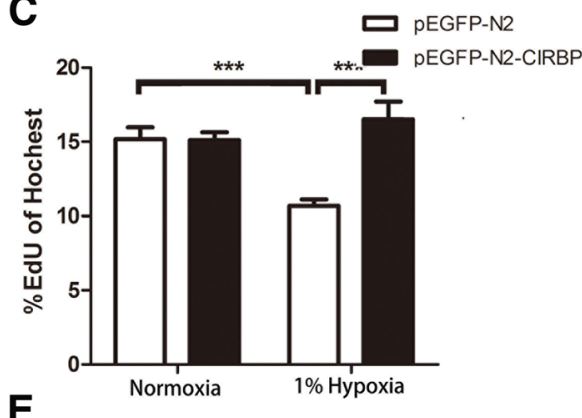

E
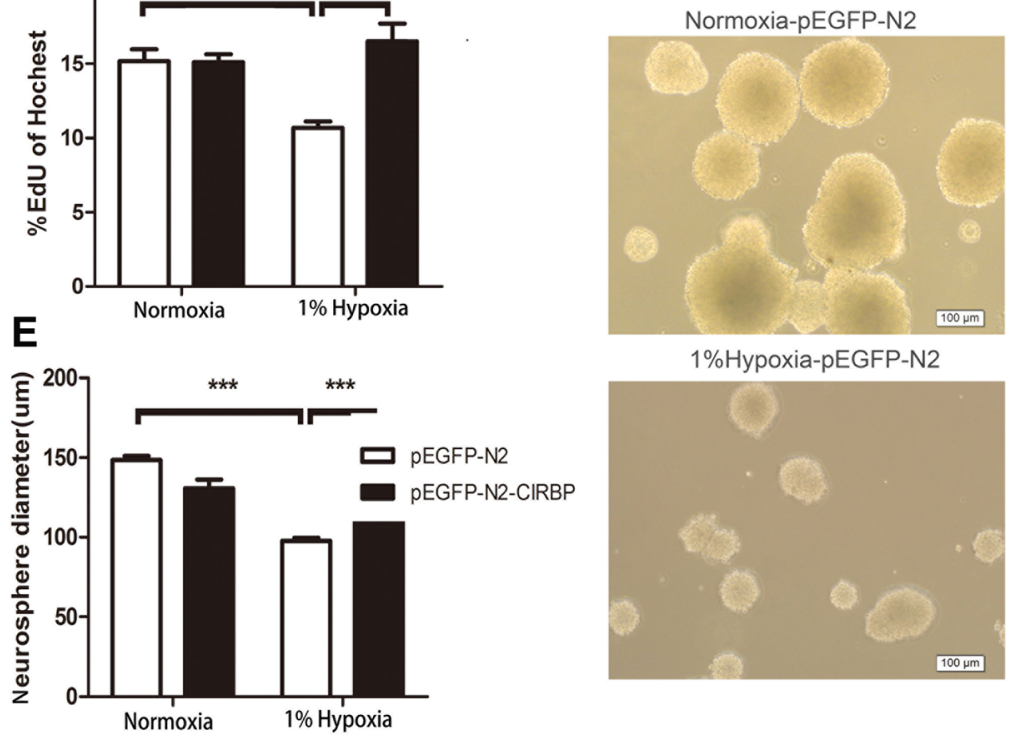

1\%Hypoxia-pEGFP-N2

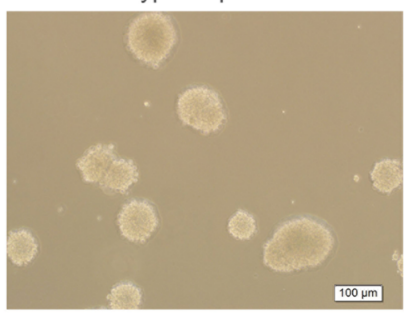

B Normoxia-pEGFP-N2

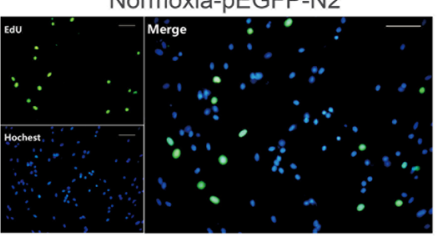

1\%Hypoxia-pEGFP-N2

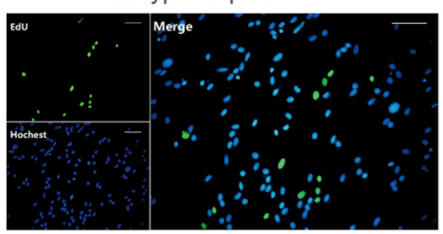

\section{D}

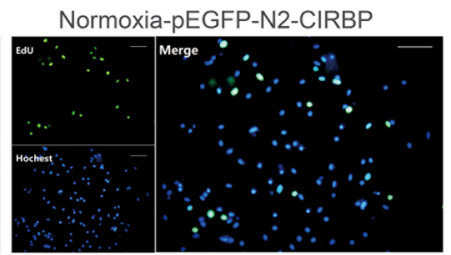

$1 \%$ Hypoxia-pEGFP-N2-CIRBP

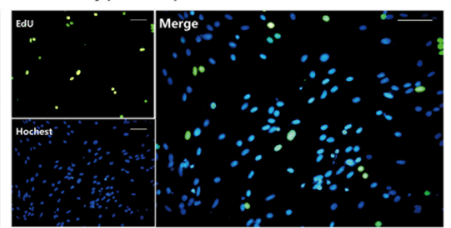



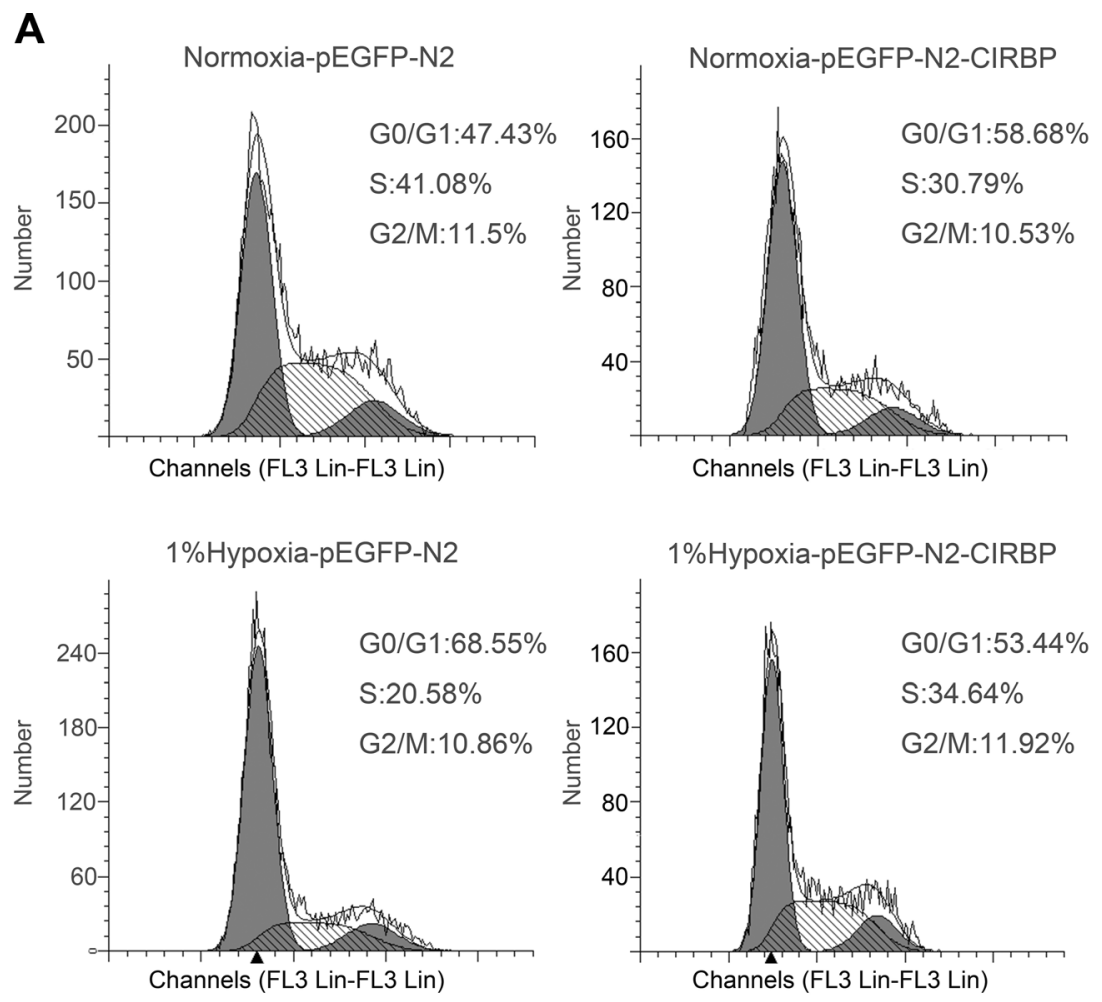

C

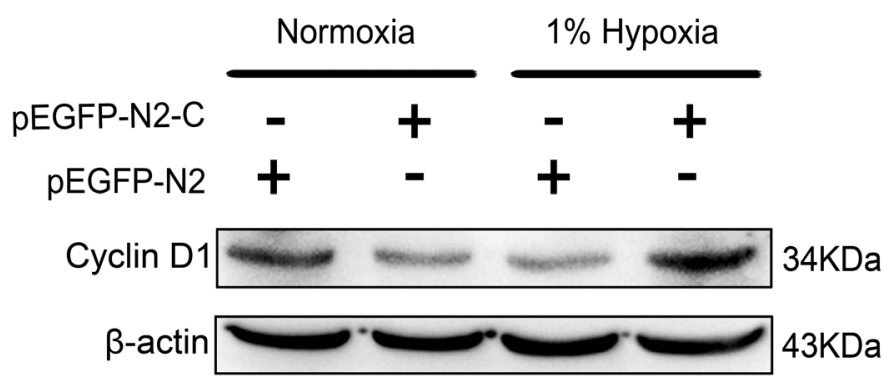

B
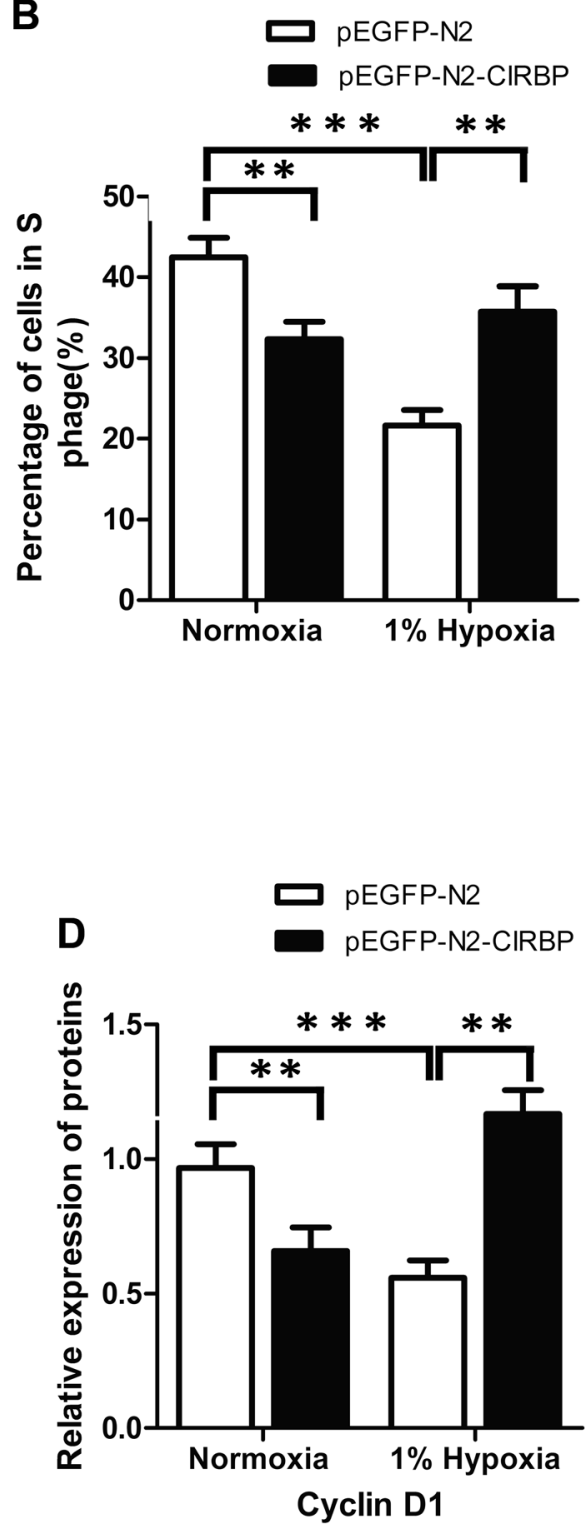

Fig. 5 Effect of CIRBP overexpression on hypoxia-induced cell cycle arrest of C17.2 NSCs. a, b Cell cycle analysis of C17.2 NSCs transfected with mock vector (pEGFP-N2) or pEGFP-N2-CIRBP (pEGFP-N2-C) that were cultured in normoxia or $1 \% \mathrm{O}_{2}$ for $24 \mathrm{~h}$. A representative plot of cell cycle from one of three independent experiments is shown (a). The first gray area (close to Yaxis), the hatched area, and the second gray area (distant to Yaxis) represent the number of cells in G1/G0, S phase, and G2

\section{Effects of CIRBP Overexpression on the Cell Cycle Arrest of NSCs Induced by Severe Hypoxia}

CIRBP has been shown to stabilize Cyclin D1 and accelerate cell cycle progression from G0/G1 to S phase in cultured mouse embryonic fibroblasts [26]. To examine the mechanism underlying CIRBP restoration of cell growth of $1 \% \mathrm{O}_{2}$-exposed NSCs, we analyzed the cell cycle distribution and the expression of Cyclin D1 in C17.2 NSCs. Under $1 \% \mathrm{O}_{2}$ exposure, transfection of p-EGFP-N2-CIRBP plasmid significantly phase, respectively. Percentages of cells in $\mathrm{G} 1 / \mathrm{G} 0, \mathrm{~S}$, and $\mathrm{G} 2 / \mathrm{M}$ phase in control and hypoxia-exposed groups were calculated with data from three independent experiments (b). c, d Western blotting analysis of Cyclin D1 in transfected cells cultured in normoxia or hypoxia for $24 \mathrm{~h}$. $\beta$-actin served as a protein loading control. $* *$ and $* * *$ indicate significant difference between compared groups $(* * p<0.01$; ***p $<0.001)$

increased the percentages of cells in S phase from 21.08 to $37.43 \%$ (Fig. 5a, b). Of note, in normal culture condition, transfection of p-EGFP-N2-CIRBP plasmid significantly reduced the percentages of cells in $\mathrm{S}$ phase from 40.62 to $30.70 \%$ (Fig. 5a, b). Furthermore, the expression of Cyclin D1 was significantly enhanced by CIRBP overexpression in hypoxia-treated cells (Fig. 5c, d). In normal culture conditions, overexpression of CIRBP exhibited an inhibitory effect on the expression of Cyclin D1 (Fig. 5c, d). Overall, these data suggest that overexpression of CIRBP may prevent the 
detrimental effects of severe hypoxia on NSC proliferation, at least partially via regulating the expression of Cyclin D1.

\section{Discussion}

In this study, we examined the effect of $1 \% \mathrm{O}_{2}$ hypoxia on the proliferation of NSCs and the possible role of CIRBP in growth arrest of NSCs under this condition. By MTT assay, EdU incorporation, and cell cycle analysis, we observed a growth-stimulating effect of $5 \% \mathrm{O}_{2}$ and a slight effect of $3 \% \mathrm{O}_{2}$ on the growth of NSCs which was consistent with previous report [35]. Interestingly, we found an obvious inhibitory effect of $1 \% \mathrm{O}_{2}$ on both $\mathrm{C} 17.2 \mathrm{NSC}$ and primarily cultured NSCs without significantly affecting cell survival. These data suggested that $1 \% \mathrm{O}_{2}$ may be used to model the severe hypoxia under pathological conditions as reported [32, $35,36]$. In our study, we focused on the effect of $\mathrm{O}_{2}$ on the proliferation of NSCs. Then by Western blotting and real time RT-PCR, we detected a decrease of CIRBP by $1 \% \mathrm{O}_{2}$. In the end, we overexpressed CIRBP and found that CIRBP could restore the growth of NSCs under $1 \% \mathrm{O}_{2}$ culture condition. These results, for the first time, revealed a role of CIRBP in the regulation of proliferation of NSCs.

During development, NSCs live in a hypoxic microenvironment [37-39]. Mild hypoxia has been demonstrated to facilitate the proliferation of NSCs through HIF-1 $\alpha$ and beta-catenin signaling $[8,40]$. Mild hypoxia has been even adopted for improving stem cell culture [41]. Severe hypoxia, which usually occurs under pathological conditions, reportedly induces NSCs to a quiescent state or apoptosis [42]. In this study, we demonstrated that $1 \% \mathrm{O}_{2}$ could induce a quick growth arrest of NSCs, suggesting a detrimental effect of severe hypoxia on NSCs, and raising the importance of further investigating the mechanism of severe hypoxia on NSCs.

CIRBP is a stress responsive gene, which is expressed in almost all the tissues. In tumor cells, CIRBP is highly expressed and thought to be an oncogene [25, 27]. In cultured mouse embryonic fibroblasts, CIRBP protein can regulate the phosphorylation and stabilization of p27 and Cyclin D1 through interacting with Dyrk1b/Mirk and accelerate cell cycle progression from $\mathrm{G} 0$ to $\mathrm{G} 1$ phase as well as from $\mathrm{G} 1$ to $\mathrm{S}$ phase [26]. Our data showed that the expression of CIRBP was inhibited in the NSCs stressed by $1 \% \mathrm{O}_{2}$ when cell proliferation was arrested. Overexpression of CIRBP can rescue the inhibitory effect of $1 \% \mathrm{O}_{2}$ on the expression of Cyclin D1 and progress of cell cycle, indicating a role of CIRBP in regulating the proliferation of NSCs.

The expression of CIRBP is regulated by various stressing factors, such as hypothermia, UV irradiation, and hypoxia $[15,17,25,43]$, to meet the functional requirement of cells under different conditions, and therefore varies depending on the injury models. In conditions of hypoxia, middle cerebral artery occlusion induces the elevation of CIRBP while transient forebrain ischemia has no significant effects on the expression of CRIBP mRNA [19, 44]. In our study, the reduction of CIRBP in accompany with the arrest of cell proliferation in NSCs under severe hypoxia is consistent with the effects of hypoxia on NSC proliferation. In the hippocampus where neurogenesis persists, CIRBP decreases quickly after ischemia [19]. In vitro, $\mathrm{H}_{2} \mathrm{O}_{2}$ treatment can inhibit the hypothermia-induced CIRBP expression $[19,45,46]$, indicating that the regulation of CIRBP by hypoxia may be reactive oxygen species (ROS)-mediated, because ROS in proper level is beneficial and ROS in higher level is toxic for NSC proliferation [45, 47, 48]. It may be possible that mild hypoxia results in mild elevation of ROS, which may then lead to CIRBP expression, while severe hypoxia induces overload of ROS, which suppresses the expression of CIRBP. Further studies are too worthy to be conducted to explore this issue.

Acknowledgments This work was supported by grants from the National Natural Science Foundation of China (no. 81330045, no. 81172621), the National Science and Technology Major Program (no. 2014ZX09J14106-03A, no. 2011ZXJ09201-023), the Program for New Century Excellent Talents in University, the Program for Changjiang Scholars (no. T2011153), and the Innovative Research Team in University. We thank Professor Yang G, PhD (Department of Biochemistry and Molecular Biology, Fourth Military Medical University) for valuable advises and guidance on the design of experiment and completion of whole tasks.

Open Access This article is distributed under the terms of the Creative Commons Attribution 4.0 International License (http:// creativecommons.org/licenses/by/4.0/), which permits unrestricted use, distribution, and reproduction in any medium, provided you give appropriate credit to the original author(s) and the source, provide a link to the Creative Commons license, and indicate if changes were made.

\section{References}

1. Caretti A, Bianciardi P, Ronchi R, Fantacci M, Guazzi M, Samaja M (2008) Phosphodiesterase-5 inhibition abolishes neuron apoptosis induced by chronic hypoxia independently of hypoxia-inducible factor-1alpha signaling. Experimental biology and medicine 233: 1222-30. doi:10.3181/0802-RM-73

2. Li, J., D. Chen, J. Tang, J. Wu, Y. Qu, D. Mu (2014a). Effect of integrin beta8 on neuronal apoptosis after hypoxia ischemia in astrocyte/neuron co-culture system. Zhongguo xiu fu chong jian wai ke za zhi=Zhongguo xiufu chongjian waike zazhi $=$ Chinese journal of reparative and reconstructive surgery 28, 366-70

3. Li L, Qu Y, Mao M (2007) Relationship between hypoxia inducible factor 1alpha: expression and neuron apoptosis during hypoxia ischemia brain damage in neonatal rats. Zhongguo xiu fu chong jian wai ke za zhi $=$ Zhongguo xiufu chongjian waike zazhi $=$ Chinese journal of reparative and reconstructive surgery 21:1326-9

4. Tan X, Guo X, Liu H (2013) Melatonin attenuates hippocampal neuron apoptosis and oxidative stress during chronic intermittent hypoxia via up-regulating B-cell lymphoma-2 and 
down-regulating B-cell lymphoma-2-associated X protein. Saudi medical journal 34:701-8

5. Zerlin M, Levison SW, Goldman JE (1995) Early patterns of migration, morphogenesis, and intermediate filament expression of subventricular zone cells in the postnatal rat forebrain. The Journal of neuroscience : the official journal of the Society for Neuroscience 15:7238-49

6. De Filippis L, Delia D (2011) Hypoxia in the regulation of neural stem cells. Cellular and molecular life sciences : CMLS 68:283144. doi:10.1007/s00018-011-0723-5

7. Panchision DM (2009) The role of oxygen in regulating neural stem cells in development and disease. Journal of cellular physiology 220:562-8. doi:10.1002/jcp.21812

8. Braunschweig L, Meyer AK, Wagenfuhr L, Storch A (2015) Oxygen regulates proliferation of neural stem cells through Wnt/ beta-catenin signalling. Molecular and cellular neurosciences 67: 84-92. doi:10.1016/j.mcn.2015.06.006

9. Perez Estrada C, Covacu R, Sankavaram SR, Svensson M, Brundin L (2014) Oxidative stress increases neurogenesis and oligodendrogenesis in adult neural progenitor cells. Stem cells and development 23:2311-27. doi:10.1089/scd.2013.0452

10. Xie Y et al (2014) Defining the role of oxygen tension in human neural progenitor fate. Stem cell reports 3:743-57. doi:10.1016/j. stemcr.2014.09.021

11. Buono KD, Goodus MT, Guardia Clausi M, Jiang Y, Loporchio D, Levison SW (2015) Mechanisms of mouse neural precursor expansion after neonatal hypoxia-ischemia. The Journal of neuroscience : the official journal of the Society for Neuroscience 35:8855-65. doi:10.1523/JNEUROSCI.2868-12.2015

12. Chicha L, Smith T, Guzman R (2014) Stem cells for brain repair in neonatal hypoxia-ischemia. Child's nervous system : ChNS : official journal of the International Society for Pediatric Neurosurgery 30:37-46. doi:10.1007/s00381-013-2304-4

13. Kanagawa T et al (2006) A decrease of cell proliferation by hypothermia in the hippocampus of the neonatal rat. Brain research 1111: 36-40. doi:10.1016/j.brainres.2006.06.112

14. Mannello F, Medda V, Tonti GA (2011) Hypoxia and neural stem cells: from invertebrates to brain cancer stem cells. The International journal of developmental biology 55:569-81. doi:10. 1387/ijdb.103186fm

15. De Leeuw F, Zhang T, Wauquier C, Huez G, Kruys V, Gueydan C (2007) The cold-inducible RNA-binding protein migrates from the nucleus to cytoplasmic stress granules by a methylation-dependent mechanism and acts as a translational repressor. Experimental cell research 313:4130-44. doi:10.1016/j.yexcr.2007.09.017

16. Liu A, Zhang Z, Li A, Xue J (2010) Effects of hypothermia and cerebral ischemia on cold-inducible RNA-binding protein mRNA expression in rat brain. Brain research 1347:104-10. doi:10.1016/j. brainres.2010.05.029

17. Nishiyama $\mathrm{H}$ et al (1997) Cloning and characterization of human CIRP (cold-inducible RNA-binding protein) cDNA and chromosomal assignment of the gene. Gene 204:115-20

18. Wellmann S et al (2004) Oxygen-regulated expression of the RNA-binding proteins RBM3 and CIRP by a HIF-1independent mechanism. Journal of cell science 117:178594. doi: $10.1242 /$ jcs. 01026

19. Xue JH et al (1999) Effects of ischemia and $\mathrm{H} 2 \mathrm{O} 2$ on the cold stress protein CIRP expression in rat neuronal cells. Free radical biology \& medicine 27:1238-44

20. Zhou M, Yang WL, Ji Y, Qiang X, Wang P (2014) Cold-inducible RNA-binding protein mediates neuroinflammation in cerebral ischemia. Biochimica et biophysica acta 1840:2253-61. doi:10. 1016/j.bbagen.2014.02.027

21. Al-Fageeh MB, Smales CM (2009) Cold-inducible RNA binding protein (CIRP) expression is modulated by alternative mRNAs. Rna 15:1164-76. doi:10.1261/rna.1179109
22. Liu Y et al (2013) Cold-induced RNA-binding proteins regulate circadian gene expression by controlling alternative polyadenylation. Scientific reports 3:2054. doi:10.1038/srep02054

23. Morf J, Schibler U (2013) Body temperature cycles: gatekeepers of circadian clocks. Cell cycle 12:539-40. doi:10.4161/cc.23670

24. Qiang X et al (2013) Cold-inducible RNA-binding protein (CIRP) triggers inflammatory responses in hemorrhagic shock and sepsis. Nature medicine 19:1489-95. doi:10.1038/nm.3368

25. Lleonart ME (2010) A new generation of proto-oncogenes: coldinducible RNA binding proteins. Biochimica et biophysica acta 1805:43-52. doi:10.1016/j.bbcan.2009.11.001

26. Masuda T et al (2012) Cold-inducible RNA-binding protein (Cirp) interacts with Dyrk1b/Mirk and promotes proliferation of immature male germ cells in mice. Proceedings of the National Academy of Sciences of the United States of America 109:10885-90. doi:10. 1073/pnas.1121524109

27. Sakurai T et al (2015) Cold-inducible RNA-binding protein promotes the development of liver cancer. Cancer science 106:352-8. doi:10.1111/cas.12611

28. Tan HK, Lee MM, Yap MG, Wang DI (2008) Overexpression of cold-inducible RNA-binding protein increases interferon-gamma production in Chinese-hamster ovary cells. Biotechnology and applied biochemistry 49:247-57. doi:10.1042/BA20070032

29. Tang $\mathrm{C}$ et al (2015) Analysis of gene expression profiles reveals the regulatory network of cold-inducible RNA-binding protein mediating the growth of BHK-21 cells. Cell biology international 39:67889. doi:10.1002/cbin.10438

30. Wang M, Zhang H, Heng X, Pang Q, Sun A (2015) Expression of cold-inducible RNA-binding protein (CIRP) in pituitary adenoma and its relationships with tumor recurrence. Medical science monitor : international medical journal of experimental and clinical research 21:1256-60. doi:10.12659/MSM.893128

31. Saito $\mathrm{K}$ et al (2010) Moderate low temperature preserves the stemness of neural stem cells and suppresses apoptosis of the cells via activation of the cold-inducible RNA binding protein. Brain research 1358:20-9. doi:10.1016/j.brainres.2010.08.048

32. Felfly $\mathrm{H}$ et al (2011) Severe hypoxia: consequences to neural stem cells and neurons. J Neurol Res 1. doi:10.4021/jnr70w

33. Snyder EY et al (1992) Multipotent neural cell lines can engraft and participate in development of mouse cerebellum. Cell 68(1): 33Cell 68(1): 33-51

34. Pavon LF et al (2014) In vitro analysis of neurospheres derived from glioblastoma primary culture: a novel methodology paradigm. Frontiers in neurology 4:214. doi:10.3389/fneur. 2013.00214

35. Santilli G et al (2010) Mild hypoxia enhances proliferation and multipotency of human neural stem cells. PloS one 5:e8575. doi: 10.1371/journal.pone.0008575

36. Zadori A et al (2011) Survival and differentiation of neuroectodermal cells with stem cell properties at different oxygen levels. Experimental neurology 227:136-48. doi:10.1016/j. expneurol.2010.10.004

37. Decimo I, Bifari F, Krampera M, Fumagalli G (2012) Neural stem cell niches in health and diseases. Current pharmaceutical design 18:1755-83

38. Lathia JD, Rao MS, Mattson MP, Ffrench-Constant C (2007) The microenvironment of the embryonic neural stem cell: lessons from adult niches? Developmental dynamics : an official publication of the American Association of Anatomists 236:3267-82. doi:10. 1002/dvdy.21319

39. Preston M, Sherman LS (2011) Neural stem cell niches: roles for the hyaluronan-based extracellular matrix. Frontiers in bioscience 3:1165-79

40. Li, L., et al. (2014b). Hypoxia inducible factor-1alpha (HIF-1alpha) is required for neural stem cell maintenance and vascular stability in 
the adult mouse SVZ. J Neurosci. 34, 16713-9 doi:10.1523/ JNEUROSCI.4590-13.2014

41. Stacpoole SR, Webber DJ, Bilican B, Compston A, Chandran S, Franklin RJ (2013) Neural precursor cells cultured at physiologically relevant oxygen tensions have a survival advantage following transplantation. Stem cells translational medicine 2:464-72. doi:10. 5966/sctm.2012-0144

42. Singh RP, Franke K, Wielockx B (2012) Hypoxia-mediated regulation of stem cell fate. High altitude medicine \& biology 13:162-8. doi:10.1089/ham.2012.1043

43. Fujita J (1999) Cold shock response in mammalian cells. Journal of molecular microbiology and biotechnology 1:243-55

44. Nishiyama $\mathrm{H}$ et al (1998) Diurnal change of the cold-inducible RNA-binding protein (Cirp) expression in mouse brain. Biochemical and biophysical research communications 245:5348. doi:10.1006/bbrc.1998.8482
45. Huang TT, Zou Y, Corniola R (2012) Oxidative stress and adult neurogenesis - effects of radiation and superoxide dismutase deficiency. Seminars in cell \& developmental biology 23:738-44. doi: 10.1016/j.semcdb.2012.04.003

46. Li S, Zhang Z, Xue J, Liu A, Zhang H (2012) Cold-inducible RNA binding protein inhibits $\mathrm{H}(2) \mathrm{O}(2)$-induced apoptosis in rat cortical neurons. Brain research 1441:47-52. doi:10.1016/j.brainres.2011. 12.053

47. Bai X et al (2013) Ketamine enhances human neural stem cell proliferation and induces neuronal apoptosis via reactive oxygen species-mediated mitochondrial pathway. Anesthesia and analgesia 116:869-80. doi:10.1213/ANE.0b013e3182860fc9

48. Lages YM, Nascimento JM, Lemos GA, Galina A, Castilho LR, Rehen SK (2015) Low oxygen alters mitochondrial function and response to oxidative stress in human neural progenitor cells. PeerJ 3:e1486. doi:10.7717/peerj.1486 